\title{
Replicability of sight word training and phonics training in poor readers: a randomised controlled trial
}

Genevieve M McArthur, Saskia Kohnen, Kristy Jones, Philippa Eve, Erin Banales, Linda Larsen, Anne Castles

Given the importance of effective treatments for children with reading impairment, paired with growing concern about the lack of scientific replication in psychological science, the aim of this study was to replicate a quasi-randomised trial of sight word and phonics training using a randomised controlled trial $(\mathrm{RCT})$ design. One group of poor readers $(\mathrm{N}=$ 41) did 8 weeks of phonics training (i.e., phonological decoding) and then 8 weeks of sight word training (i.e., whole-word recognition). A second group did the reverse order of training. Sight word and phonics training each had a large and significant valid treatment effect on trained irregular words and word reading fluency. In addition, combined sight word and phonics training had a moderate and significant valid treatment effect on nonword reading accuracy and fluency. These findings demonstrate the reliability of both phonics and sight word training in treating poor readers in an era where the importance of scientific reliability is under close scrutiny. 

controlled trial

11 G. McArthur (PhD), S. Kohnen (PhD), K. Jones (BSc Hons), P. Eve (BSc Hons), E. Banales, (PhD), L.

16 Correspondence

17 A/Prof Genevieve McArthur

18 Department of Cognitive Science

19 Macquarie University NSW 2109

20 Australia

21 genevieve.mcarthur@mq.edu.au

$22+61298509162$ 


\section{Introduction}

Around 5\% of children have a significant reading impairment despite normal reading instruction, normal intelligence, and the absence of any known neurological or psychological problems. This

31 condition - often called developmental dyslexia (Hulme \& Snowling, 2009) - not only affects a child's academic achievements, but increases their risk for anxiety, depression, conduct disorder, and

33 hyperactivity (Carroll, Maughan, Goodman, \& Meltzer, 2005). Thus, it is critical to discover how to 34 treat poor readers as early and effectively as possible.

To date, most treatment trials done with poor readers have looked at the effects of "phonics" reading programs, which teach children to learn to explicitly "phonologically decode" words by converting graphemes (i.e., letters or letter clusters; e.g., ship) into sounds (e.g., sh as in cash, i as in in, and $\mathrm{p}$ as in pin) and then blend those sounds into a word ("ship"). Since the turn of the century, at least three systematic reviews and meta-analyses have examined the effect of phonics training in poor readers. In 2001, Ehri, Nunes, Stahl, and Willows (2001) reported that phonics training, administered

41 either alone or in combination with other types of training (e.g., phoneme awareness), had a moderate 42 effect on poor readers' explicit phonological decoding, but a small effect on their word reading. In 43 2012, McArthur et al. (2012) reported that "specific" phonics training, which focused on explicit

44 phonological decoding with minimal training in other skills, had a large effect on poor readers' explicit 45 phonological decoding, a moderate effect on their word reading, and a small-to-moderate effect on 46 their grapheme-phoneme correspondence (GPC) knowledge. In 2014, Galushka, Ise, Krick, and 47 Schulte-Korne (2014) reported that specific phonics training had a small but significant effect on 48 reading measures averaged across different reading tests. Considered together, the outcomes of these 49 reviews suggest that phonics training in poor readers might have significant and large effects on 50 reading measures that depend heavily on explicit phonological decoding, but weaker effects on reading 
51 measures that depend on other skills, such as "sight word reading" (i.e., recognizing whole words from

52 orthographic memory) and "reading comprehension" (i.e., understanding the meaning of written texts). The outcomes of these systematic reviews align with the two widely used cognitive models of 54 word reading: the dual route model and the triangle model (e.g., Coltheart, Rastle, Perry, Langdon, \& 55 Ziegler, 2001; Plaut, Seidenberg, McClelland, \& Patterson, 1996). According to both models, printed 56 letters trigger cognitive processes relating to letter identification, the outputs of which are fed through to two pathways: (1) a "sublexical route" (dual route model)/ "phonological pathway" (triangle model); and (2) a "lexical route" (dual route model)/“semantic pathway" (triangle model). The sublexical/phonological pathway, which includes links between orthography and phonology, makes a greater contribution to reading "regular" words (i.e., real words that can be read correctly via explicit

61 phonological decoding, e.g., ship) and "nonwords" (i.e., nonsense words that can be read accurately via explicit phonological decoding, e.g., shap). In contrast, the lexical/semantic pathway, which has links between orthography, phonology, and semantics, makes a greater contribution to reading "irregular" words (i.e., words that cannot be read accurately via explicit phonological decoding alone, e.g., yacht). Both the dual route and triangle models predict that phonics training should have its largest impact on the sublexical/phonological pathway, and hence the ability to read regular words and nonwords. This prediction is supported by the aforementioned systematic reviews by Ehri et al.,

68 (2001), McArthur et al. (2012), and Galushka et al (2014) that suggest phonics training in poor readers

69 has its largest effect on reading measures that depend most heavily on explicit phonological decoding 70 (e.g., reading regular words and nonwords). The dual route and triangle models further predict that training sight word reading (i.e.,

72 recognizing whole words from orthographic memory) should have its largest effect on the

73 lexical/semantic pathway, and hence the ability to read irregular words. Unfortunately, there is little 74 empirical data to test this prediction since most studies that examined the effects of sight word training 
on reading have included both regular and irregular words as training stimuli. The inclusion of regular

words is problematic because, as hypothesized by the dual route and triangle models, regular words can be read with the sublexical/lexical pathway. Thus, the inclusion of regular words in sight word training obscures the true effect of training the lexical/semantic pathway. In order to test this effect, it is important to employ "specific sight word training" that focuses training on recognizing written irregular words "by sight” (i.e., from orthographic memory).

To our knowledge, only one controlled trial has investigated the effect of specific sight word training in poor readers. McArthur et al. (in press) gave three groups of children with poor reading different orders of sight word and phonics training. Group $1(\mathrm{~N}=36)$ received 8 weeks of "specific phonics training" (i.e., training reading via grapheme-phoneme correspondence (GPC) rules alone) followed by 8 weeks of specific sight word training (training the recognition of irregular words from memory). Group $2(\mathrm{~N}=26)$ received the same training in reverse order. Group 3 received "mixed" training that comprised the phonics training and sight word training on alternate days for two 8-week periods $(\mathrm{N}=32)$. The outcomes revealed that: (1) specific sight word training had large and significant valid treatment effects on trained irregular words, untrained irregular words, word reading fluency, and word reading comprehension, as well as a moderate and significant treatment effect on nonword reading accuracy, and no treatment effect on nonword reading fluency; (2) specific phonics training had large and significant "valid" treatment effects (i.e., significantly larger than test-retest effects) on trained and untrained irregular words, word and nonword reading fluency, and reading comprehension, as well as a moderate-to-large effect on nonword reading accuracy; and (3) order of training (i.e., phonics-then-sight words; sight words-then-phonics; mixed) had an effect on untrained irregular word reading (significantly better after phonics-then-sight word training, than the reverse) but not on trained irregular words, nonword reading accuracy or fluency, word reading fluency, or reading 
98 comprehension (see Table 1 for a summary of the effects found by McArthur et al. compared to the 99 current study).

100

101

102

103

104

105

106

107

108

109

110

111

112

113 114 above.

115

116

117

118

119

120

121

Please insert Table 1 about here

Finding (1) was exciting because it showed, for the first time in a controlled group trial (albeit quasi-randomised), that specific sight word training has significant and large treatment effects in children with poor reading. Finding (2) was reassuring since it supported conclusions of the aforementioned meta-analyses that reported moderate to large phonics effects on some reading skills in poor readers. Finding (3) was puzzling since it appears to be often assumed by clinicians and researchers (despite the absence of empirical evidence) that poor readers should be taught explicit phonological decoding prior to sight word reading (Chall, 1967).

Given the importance of finding reliably effective treatments for poor readers, paired with growing concern about lack of replication in psychological and cognitive scientific research (e.g., Drotar, 2010; Ioannidis, 2012; Pashler \& Harris, 2012; Wagenmakers, Borsboom, van der Maas, \& Kievit), the aim of the current study was to test the replicability of McArthur et al.'s quasi-randomised controlled reading treatment trial. To this end, we used randomised controlled trial (RCT) that closely replicated the methods of McArthur et al. to test the replicability of key findings (1) to (3) outlined Materials and methods

The Macquarie University Human Research Ethics Committee (Ref: 5201200852) approved the methods outlined below. All children and their parents gave their informed consent to participate in this RCT. Children were continuously recruited into the study between January 2011 and June 2013 (i.e. children were not all tested and trained at the same point in time). Since it took 6 months for a child to complete the study, the last child completed the last test session (Test 4) in December 2013. This trial is registered with the Australian New Zealand Clinical Trials Registry (ANZCTR; 
122 12608000454370). Methodological differences (all minor) between McArthur et al. (in press) and the

123 current study are outlined in parentheses.

\section{Trial design}

125 All children completed screening and outcome measures at Test 1 (see Figure 1). After 8 weeks

126 of no training, they returned to do the outcome measures (Test 2) to index "non-treatment gains" (i.e.,

127 due to test-retest effects, test situation familiarity, regression to the mean, maturation, and a "test-

128 related Hawthorne effect" resulting from an awareness of being tested multiple times on similar

129 outcome measures). Group 1 did 8 weeks of phonics training (and then Test 3) followed by 8 weeks of

130 sight word training (and then Test 4). Group 2 did the same training in the reverse order. In the

131 analysis, we controlled for non-treatment gains when comparing phonics training to sight word

132 training, and when comparing phonics-then-sight word training versus sight word-then-phonics

133 training (Note: unlike McArthur et al. (in press), we did not include a "mixed" group since this group

134 showed no advantage over groups 1 and 2 in in McArthur et al.)

Please insert Figure 1 about here

\section{Participants}

137 In line with McArthur et al. (in press), this study recruited a typical "mixed" sample of poor

138 readers from the community. Children were aged from 7 to 12 ; scored below the average range for

139 their age (i.e., had a $\mathrm{z}$ score lower than -1.0 , which represents the lowest $16 \%$ of readers) on the Castles

140 and Coltheart 2 (CC2) irregular-word reading test and/or nonword reading test (Castles, Coltheart,

141 Larsen, Jones, Saunders, \& McArthur, 2009; see below); had no history of neurological or sensory

142 impairment as indicated on a background questionnaire; and used English as their primary language at

143 school and at home (see Screening Tests below). This resulted in a sample that was very similar in age,

144 nonverbal IQ, and irregular word reading as McArthur et al. (see Table 2). However, the mean CC2

145 nonword reading scores for groups 1 and 2 in McArthur et al. (-1.50 and -1.27, respectively) were 
146 higher than in the current study (-1.66 and -1.62 , respectively). Similarly, the mean CC2 regular word

147 reading scores for groups 1 and 2 in McArthur et al. (-1.41 and -1.29, respectively) were higher than in

148 the current study (-1.61 and -1.57 , respectively). Thus, on average, children in the current study had

149 slightly poorer explicit phonological decoding abilities than children in McArthur et al. (in press).

Please insert Table 2 about here

\section{Interventions}

Specific sight word training. Children were asked to do five 30-minute sight-word training

sessions per week for 8 weeks in their homes. The sight word training used an online reading program

called Literacy Planet (www.literacyplanet.com) to deliver exercises (see below) to teach children to

recognise the same irregular words (see below) used by McArthur et al. (Note: McArthur et al. used

only two exercises to teach irregular words: one administered by computer (DingoBingo by

Macroworks) and the other by a parent). Children received immediate feedback on the accuracy of

their responses, which earned them points to spend on games or clothing their avatar on the

LiteracyPlanet site. LiteracyPlanet also provided online access to the progress of the children in

training time and performance level. This allowed the research team to detect when a child was failing to complete the required amount of training, in which case the parents were contacted to discuss how the children could better continue training. selected using the following procedure: (1) REGCELEX in the CELEX database of children's written words was used to compute the rule-based pronunciations of each word in said database; (2) these pronunciations were compared to each word's dictionary pronunciation; (3) any word with a mismatch

167 between its computer pronunciation and dictionary pronunciation was selected; (4) from this list we 168 removed proper nouns and rude words, low frequency words that would seldom be encountered by 
169 children, and words included in $\mathrm{CC} 2$; (5) we ordered the words in terms of difficulty based on their 170 written frequency, which ranged from 507073 (for of) down to 8 ( for scone).

171 The irregular words were trained across 56 levels in Literacy Planet. Each level used eight or 172 nine exercises to train a list of words. The lists for levels 1-30, 31-48, and 49-56 comprised 8, 14, and

17324 words, respectively. The exercises for levels 1-9 included: Flash Card, Alphabetical Word Monster,

174 Static Words, Word Snap, Floating Words, Word Finder, Word Builder 2, Spell This Word, and Word

175 Builder 1. Levels 10-56 used the same exercises except for Word Finder. For each exercise, children

176 were required to reach an achievement level of $80 \%$ before progressing to the next exercise. This was

177 lower than the achievement level required by the phonics training (i.e., $100 \%$, see below) since some of

178 the exercises were more difficult than those in the phonics training, and we wanted the children to be

179 able to achieve pass-rate status at a reasonable rate, and without frustration.

180 In the Flash Card exercise, children were asked to spell a written word that that was presented on

181 the screen and then covered. In Alphabet Monster, children were instructed to drag words presented in

182 a list into a monster's mouth in alphabetical order. In Static Words, children were shown a static array

183 of written words, and asked to click on a word that they heard. In Floating Words, they did the same

184 thing except that the selection of words floated around the screen. In Word Snap, children were shown

185 two words, and asked to click SNAP when the two words matched. In Word Finder, children were

186 shown a matrix of letters and asked to select the first and last letter of a word that they heard. In the

187 two Word Builder exercises, children were presented with the letters of a spoken word in mixed order,

188 and asked to spell that word. In Spell This Word, children clicked on one of a number of bush flies on

189 the screen, which triggered a spoken word. They were asked to spell the word.

190 Specific phonics training. LiteracyPlanet was also used to deliver phonics training to the

191 children for 30 minutes per day, 5 days per week, for 8 weeks in their homes. We taught phonics used

192 nine exercises (see below) across 220 levels that increased in difficulty to train the explicit 
193 phonological decoding and encoding of consonants, short vowels, long vowels, blends, digraphs, the

194 bossy e rule, plurals, soft 'c' and 'g', dipthongs, 'r' sounds, and Silent Letters. No exercises included

195 irregular words, sentences, or paragraphs of text (Note: McArthur et al. (in press) used a similar

196 number of CDROM-based computer games from Lexia Strategies for Older Students to teach children

197 to decode and encode the same stimuli). In line with the sight word training, children received

198 immediate feedback on the accuracy of their responses, which earned them points to spend on games or

199 their avatar; and we had online access to children's progress, allowing us to contact parents to discuss

200 motivational strategies if children were failing to complete their training. Children were required to

201 reach an achievement score of $100 \%$ on an exercise before moving onto the next exercise. If this was

202 not achieved, the child repeated the exercise until they reached $100 \%$.

203 In the introductory exercise - the "Movie" exercise - children were introduced to letters or letter

204 clusters and taught their corresponding letter sound. In an "I Spy" exercise, children were presented

205 with a number of pictures, a written letter, and a spoken letter sound. They were told that they could

206 click on the letter to hear the letter sound, and were asked to click on the picture that started with the

207 letter sound. In a "Letter-Sound Position" exercise, children were shown a written word and presented

208 a spoken letter sound. They were asked to indicate whether the letter sound occurred at the beginning

209 or end of the written word. In two "Missing Letters" exercises, children were asked to type in the

210 missing letter of a written word. In a "Click On Words" exercise, children were shown a number of

211 regular words, and asked to click on the word that matched a picture. In a "Bingo" exercise, children

212 were shown a number of regular words in a matrix and were presented a spoken word. They were

213 asked to click on the written version of the spoken word. In a "Spelling" exercise, children were asked

214 to type in a regular word indicated by a picture. And in a "Blending" exercise, they were asked to click

215 on letters that represent the sounds in a picture (e.g., they click on "LK" corresponding to a picture of

216 SILK). 


\section{Screening tests}

218 CC2 reading test. The CC2 comprises 40 nonwords (e.g., GRENTY), 40 irregular words (e.g.,

219 YACHT), and 40 regular words (e.g., MARSH) that increase in difficulty. The three types of stimuli

220 were presented in an interleaved fashion on index cards. Testing for any type of item (nonwords,

221 irregular words, regular words) was discontinued when a child made five consecutive errors for a

222 particular type of item, or when the child reached the end of the test. A child was given 5 seconds to

223 read each word before being prompted to try the next word. Scores were $\mathrm{z}$ scores that had a mean of 0 224 and SD of 1.

Nonverbal IQ. This was indexed with the Kaufman Brief Intelligence Test 2 (KBIT-2) Matrices subtest (Kaufman \& Kaufman, 2004). Scores were standardised with a mean of 100 and an SD of 15.

Developmental history. We used a parent questionnaire to determine if children had any known problems with their hearing, vision, neurology, or psychology, as well as establish if the children used

229 English as their primary language at both school and home.

230

\section{Primary outcomes}

Trained and untrained irregular words. Children were asked to read aloud 58 irregular words printed on flashcards. Half of the words were included in the sight word training program ("trained irregular words") and half were not ("untrained irregular words"). Untrained irregular words were matched to the trained irregular words in terms of their written frequency, length in letters, and relative irregularity (i.e., the proportion of irregular GPCs in a word relative to the total number of GPCs in that word). Scores were total correct trained irregular words (out of 29) and total correct untrained irregular words (out of 29; Note: This is the same test used by McArthur et al. less two items).

Nonword reading accuracy. This was tested using 39 untrained nonwords. A child was asked to read each nonword aloud. All items were monosyllabic, comprised 3 or 4 letters (e.g., vib, golk), and translated to two, three or four sounds. Half the items contained digraphs (e.g., th, sh), and half single- 
241 letter correspondences (e.g., t, h). Scores were total correct out of 30 (Note: McArthur et al. report that

242 their untrained nonword test comprised 20 items but we have confirmed this was an error, and this test

243 comprised 30 items, which were all included in the current test).

244 Nonword reading fluency. We indexed nonword reading fluency using the Test of Word

245 Reading Efficiency (TOWRE) nonword subtest (Torgesen, Wagner, \& Rashotte, 1999). This

246 comprised 63 increasingly difficult nonwords that can be read correctly using the letter-sound rules. A

247 child was asked to read as many nonwords as possible in 45 seconds. Scores were the total responses

248 correct out of 63.

249 Word reading fluency. This was tested with the TOWRE sight word subtest that comprised 104 250 words that increased in difficulty (Torgesen et al., 1999). A child was asked to read as many words as 251 possible in 45 seconds. Scores were the total responses correct out of 104.

Reading comprehension. This was tested using the Test of Everyday Reading Comprehension 253 (TERC) which included 10 "everyday" reading stimuli, such as a text message, a medicine label, or a 254 shopping list (McArthur, Jones, Anandakumar, Larsen, Castles \& Coltheart, 2012). For each stimulus, 255 children were asked two literal questions based on information in the text. Scores were the total 256 responses correct out of 20 (Note: McArthur et al. (in press) used a previous version of this test that 257 comprised an addition 3 stimuli and 6 questions).

\section{Sample size}

A flow diagram of the number of participants in each stage of the study is shown in Figure 2. At 260 the end of the study, there were 41 children in Group 1 and 44 children in Group 2.

\section{Sequence generation}

263 Children were allocated to groups using minimisation randomization (balanced 1:1 for age, CC2 264 nonword reading, CC2 irregular word reading; executed using MINIMPY; Mahmoud Saghaei, 2011), 
265 which is considered the most appropriate sequence allocation procedure for trials comprising fewer 266 than 100 participants. It is considered methodologically equivalent to randomization by CONSORT

267 (Schulz, Altman \& Moher, 2010; Note: McArthur et al. (in press) used a quasi-randomised allocation 268 procedure).

269 Allocation concealment and implementation

270 The lead research assistant on the project allocated children to each group and arranged their

271 training. They concealed group allocation from research assistants who conducted the test session. All

272 training was done online at home. All instructions to parents were provided via written documents.

273 Parents contacted the lead research assistant if unclear about any aspect of the training.

274 Blinding

275 Unlike drug trials, it is difficult to guarantee double blinding in cognitive treatment studies.

276 However, parents and children were not told their group allocation, and all children received exactly

277 the same type of training (in different orders). Most parents and children lack the expertise to

278 discriminate between different types of reading. In addition, no tester assessed the same child twice,

279 and no tester was aware of the child's group allocation (i.e., the tester was blind to group allocation).

280 Thus, it is highly likely this study used a double-blind procedure.

Results

282 Participant flow

A flow diagram of the number of participants in each stage of the study is shown in Figure 2. 41

284 successfully completed the phonics-then-sight word training (Group 1), and 44 successfully completed 285 the sight word-then-phonics training (Group 2). We included all children in the final analysis who 286 completed their training, bar one child whose mother admitted at the end of the study that her child had 287 been participating in another reading intervention. Participants who withdrew from the training did so 
288 for various personal reasons. Thus, the drop out rate in this study was low, and reasons for drop out 289 appeared random.

290 Baseline data

291 Between groups t-tests revealed that the two training groups did not differ significantly on the 292 screening and outcome measures prior to training (i.e., see Table 2).

\section{Training fidelity}

Based on McArthur et al. (in press), we predicted that by asking children to train for five 30-

295 304 data). minute sessions per week for 8 weeks (20 hours in total), at a minimum they would manage four 20minute session per week for 7 weeks (due to illness, holidays, and the occasional "bad day"; a minimum of 9 hours and 20 minutes). Two children from each group failed to reach this minimum, and were excluded from the final analysis. On average, the final sample completed around 14 hours for each program (see Table 2). There was no significant difference between groups in training times.

\section{Numbers analysed}

The analyses included 41 children in Group 1 and 44 children in Group 2. We analysed the data of participants in the groups to which they were originally allocated. In line with McArthur et al. (in press), we conducted an available case analysis on the data (i.e., based on participants with complete

\section{Outcomes}

Figure 3 shows each group's mean and 95\% confidence interval (CI) for gains in raw scores (i.e., difference scores) for each outcome measure. The first three CIs in each graph represent Group 1, and the last three CIs represent Group 2. Within each group, the first CI (T1T2) represents gains in raw scores from Test 1 (before training) to Test 2 (after 8 weeks of no training) due to non-training effects.

The second CI (T1T3) reflects gains in raw scores between Test 1 (before training) and Test 3 (after the 
311 first 8 weeks of training). The third CI (T1T4) reflects gains in raw scores between Test 1 (before

312 training) and Test 4 (after 16 weeks of training).

313

Please insert Figure 3 about here

Any T1T2 CI marked with * represents a statistically significant gain due to non-training effects. Any T1T3 or T1T4 CI marked with ** represents a statistically significant gain that is significantly larger than non-training effects. Only gains marked ** were considered "valid training effects". For each effect, we calculated Cohen's d effect sizes calculated from the difference scores (i.e., mean group difference score/ SD group difference score; Howell, 2010). Cohen's d scores of 0.3, 0.5, and 0.8 were considered to represent small, medium, and large effect sizes, respectively. Effect sizes for each outcome measure are compared to McArthur et al. (in press) in the Table 1.

To determine if there was a reliable difference between 8 weeks of phonics and sight word training, we used a between-group ANCOVA (controlling for each group's corresponding non-training gains measured over the T1T2 no-training period) to compare T1T3 gains for Group 1 and Group 2. To determine if different orders of training had different effects on each outcome, we used a betweengroups ANCOVA (controlling for non-training gains) to compare T1T4 gains for each group.

Trained irregular word accuracy. Eight weeks of phonics training had a moderate-to-large significant valid training effect on trained irregular words (Cohen's $d=0.70$ ). Eight weeks of sight word training had a very large significant valid treatment effect on this outcome $(\mathrm{d}=1.05)$. The difference between these effects was not statistically significant $(F(1,81)=0.62, p=.44)$. Sixteen weeks of sight word and phonics training (in either order) had very large and significant valid training effects on trained irregular word accuracy $(\mathrm{d}=1.04$ for Group 1 and $\mathrm{d}=1.39$ for Group 2$)$. The difference between these effects was not statistically significant $(F(1,82)=0.21, p=.64)$.

Untrained irregular word accuracy. Eight weeks both phonics training $(d=0.79)$ and sight word training $(\mathrm{d}=0.87)$ had large and significant valid training effects on untrained irregular word 
reading accuracy. The difference between these effects was not statistically significant $(\mathrm{F}(1,81)=0.08$, $\mathrm{p}=.78$ ). Sixteen weeks of phonics and sight word training (in either order) had very large and significant valid training effects on untrained irregular word accuracy (Group $1 \mathrm{~d}=1.14$; Group $2 \mathrm{~d}=$ 1.10). The difference between these effects was not statistically significant $(F(1,82)=0.12, p=.73)$. Nonword reading accuracy. Eight weeks of phonics training had a small non-significant effect on reading untrained nonwords $(\mathrm{d}=0.29)$. Eight weeks of sight word training had a slightly negative non-significant effect on this outcome $(d=-0.10)$. The difference between these effects was not statistically significant $(\mathrm{F}(1,81)=2.86, \mathrm{p}=.10)$. Sixteen weeks of phonics and sight word training (in either order) had a small-to-moderate significant valid training effect on nonword reading accuracy (Group $1 \mathrm{~d}=0.42$; Group $2 \mathrm{~d}=0.38$ ). The difference between these effects was not statistically significant $(\mathrm{F}(1,81)=0.21, \mathrm{p}=.65)$.

Nonword reading fluency. Eight weeks of phonics training had a small non-significant effect on nonword reading fluency $(\mathrm{d}=0.24)$. Similarly, 8 weeks of sight word training had a small nonsignificant effect on the same outcome $(d=0.25)$. The difference between these effects was not statistically significant $(\mathrm{F}(1,82)=1.33, \mathrm{p}=.25)$. Sixteen weeks of phonics-then-sight word training had a small non-significant effect on nonword reading fluency $(0.31)$ while 16 weeks of sight wordthen-phonics training had moderate-to-large significant valid training effect on nonword reading fluency $(d=0.67)$. The difference between these effects was not statistically significant $(F(1,82)=$ $0.98, \mathrm{p}=.32)$

Word reading fluency. Eight weeks of phonics training had a large significant valid training effect on word reading fluency $(\mathrm{d}=0.89)$. Eight weeks of sight word training had a very large significant valid treatment effect on this outcome $(\mathrm{d}=1.39)$. The difference between these effects was not statistically significant $(\mathrm{F}(1,82)=1.94, \mathrm{p}=.17)$. Sixteen weeks of phonics-then-sight word training had an extremely large significant valid training effect on word reading fluency $(\mathrm{d}=1.77)$, 
while sight word-then-phonics training had a very large significant valid training effect $(\mathrm{d}=1.16)$. The difference between these effects just failed to reach statistical significance $(F(1,82)=3.77, p=.06)$.

Reading comprehension. While 8 weeks of both phonics training and sight word training showed significant large or medium $(d=0.81$ and $d=0.65$, respectively) gains on reading comprehension, these gains were not significantly larger than the non-training gains, and so were not considered valid training effects. The difference between these effects was not statistically significant $(\mathrm{F}(1,82)=1.82, \mathrm{p}=.18)$. However, 16 weeks of phonics-then-sight word training had a very large significant valid training effect $(\mathrm{d}=1.01)$ on reading comprehension, and 16 weeks of sight word-thenphonics training had a large significant training effect on this outcome $(d=0.75)$. The difference between these effects was not statistically significant $(F(1,82)=1.77, \mathrm{p}=.19)$.

\section{Discussion}

\section{Main findings}

The aim of the current study was to test the replicability of the sight word and phonics training effects in poor readers reported by McArthur et al. (in press). Regarding sight word training, McArthur et al. found that specific sight word training had (1) large and significant valid treatment effects on trained irregular words (replicated in this study: $d=1.0$ ), untrained irregular words (replicated in this study: $d=0.9$ ), word reading fluency (replicated in this study: $d=1.4$ ), and word reading comprehension (not replicated in this study: non-significant $d=0.6$ ); (2) a moderate and significant valid treatment effect on nonword reading accuracy (not replicated in this study: $d=-0.1$ ); and (3) no valid treatment effect on nonword reading fluency (replicated in this study: non-significant $\mathrm{d}=0.2$ ). Thus, the current study replicated all bar two of the sight word training effects found by McArthur et al. (in press).

In the light of McArthur et al.’s significant and valid sight word treatment effects on reading nonwords and reading comprehension, our non-significant sight word training effects on these skills 
383 were somewhat puzzling. However, in light of dual route and triangle models of reading, these

384 outcomes made sense. Our specific sight word training used irregular words to maximize training the

385 lexical/semantic pathway, and minimize training the sublexical/phonological pathway. This, in turn,

386 minimized the training of cognitive skills that underpin the ability to read nonwords (i.e., explicit

387 phonological decoding). In addition, our sight word training, which trained the ability to read and spell

388 irregular words by sight, did not train the types of words (typically regular words) that were used as

389 stimuli in the reading comprehension test. Thus, the puzzle is not so much why the current study failed

390 to find a valid sight word training effect on nonword reading and reading comprehension, but why

391 McArthur et al. did, since they used very similar methods.

Given that McArthur et al. (in press) and the current study represent the only two group

393

394

395

396

397

398

399

400

401

402

403

404

405

406

controlled trials of specific sight word training (i.e., using irregular words to train the ability to

recognise words from memory) in poor readers, we must turn to a single case study by Broom and

Doctor (2008) for insight. This study examined the effect of specific sight word training (i.e., training

irregular words) on reading comprehension in an 11-year-old child with developmental surface

dyslexia. Like McArthur et al. (in press) and the current study, specific sight word training had a

significant effect on both trained and untrained irregular words. In accord with the current study, but

not McArthur et al., it did not have an effect on reading comprehension. The authors suggest, and we

concur, that their specific sight word training did not generalise to reading comprehension because

their training did not provide the explicit opportunity to apply newfound word reading skills in a

reading-comprehension context.

Moving onto phonics training, which trained explicit phonological decoding (reading) and

encoding (spelling), McArthur et al. (in press) found that specific phonics training had (1) large and significant effects on trained irregular words (replicated in this study: $d=0.7$ ), untrained irregular

words (replicated in this study: $d=0.8$ ), nonword reading fluency (not replicated in this study: $d=0.2$ ),

Peer] reviewing PDF | (2014:10:2922:4:0:REVIEW 1 Apr 2015) 
407 word reading fluency (replicated in this study: $\mathrm{d}=0.9$ ) and reading comprehension (replicated in this 408 study: $\mathrm{d}=0.9$ ); and (2) a moderate-to-large effect on nonword reading accuracy (not replicated in this 409 study: $d=0.3$ ). Thus, like the sight word training, the current study replicated all bar two of the 410 phonics training effects found by McArthur et al. (in press).

411 While the current study did not replicate the moderate-to-large phonics training effects on

412 nonword reading found by McArthur et al. (in press), it is not the case that phonics had no effect on

413 nonword reading at all. Figure 3 shows that Group 1 made gains in their nonword accuracy and fluency 414 over their 8 weeks of phonics training that were clearly larger than their non-training gains. However, 415 these gains just failed to reach statistical significance. After a further 8 weeks of training, Group 1's 416 gains became statistically significant due to minor additional gains made over 8 weeks of sight word 417 training. Group 2's data show exactly the same pattern of results but in the reverse order (i.e., because 418 they did phonics training after sight word training). Thus, the outcomes of the current study suggest 419 that phonics training did have an effect on nonword reading accuracy and fluency, but this effect was 420 certainly smaller than the effect found by McArthur et al.

421 Why might this be the case? Since the current study used very similar methods to McArthur et al. 422 (in press), the answer most likely lies with our sample. As noted under Participants, groups 1 and 2 in 423 the current study had slightly weaker explicit phonological decoding abilities than groups 1 and 2 in 424 McArthur et al. Such children may respond less well to phonics instruction (Galushka et al., 2004), 425 which would explain why the current study found smaller effects of phonics training on tests that tax 426 phonics-related skills such as nonword reading accuracy and fluency.

427 Finally, in terms of order training, McArthur et al. (in press) found that order of sight word and 428 phonics training only had an effect on untrained irregular word reading, which was significantly better 429 after phonics-then-sight word training than sight word-then-phonics training. This was not observed in 430 the current study. The closest thing we found to an order effect was for word reading fluency, which 
431 was markedly higher after phonics-then-sight word training than the reverse. However, this order effect

432 just failed to reach statistical significance. Combined with the outcomes of McArthur et al., this finding

433 suggests that order of phonics and sight word training may not matter in poor readers aged from 7 to 12

434 years who have some phonics related skills (i.e., who can read at least a few nonwords). To a certain

435 extent, this makes sense in terms of the dual route and triangle models of word reading, which make no

436 predictions about the effect of training one pathway (e.g., the sublexical/phonological pathway) before

437 another (e.g., the lexical/semantic pathway). However, this finding does not align with the assumption

438 that poor readers should be taught explicit phonological decoding prior to sight word reading (Chall,

439 1967). Whether or not an order effect might apply to poor readers with no phonics-related skills at all

440 remains an empirical investigation at this point in time.

\section{Limitations}

442 Because the current study is a replication of McArthur et al. (in press), it necessarily shares some 443 of its limitations. One was the use of a "within-subjects" control group to index non-treatment gains

444 (i.e., from Test 1 to Test 2) rather than a separate "between-subjects" untrained group (i.e., from Test 1

445 to Test 2 to Test 3 to Test 4). McArthur et al. (in press) chose to use a within-samples control group for 446 three reasons. First, children in a between-subjects control group may produce different (e.g., smaller)

447 non-treatment gains than children in a within-subjects control group, which may lead to over-

448 estimations of a treatment effect. Second, recruiting a between-subjects group would delay the

449 administration of potentially effective treatment for poor readers for 6 months during a critical period

450 of their reading development. And third, it is more difficult to recruit poor readers for a study in which

451 there is a high chance of being allocated to an untreated control group.

452 The use of a within-subjects control group in both McArthur et al. (in press) and the current study

453 allowed the explicit measurement of non-training effects from Test 1 to 2 (T1T2), but not from Test 1

454 to 3 (T1T3), or from Test 1 to 4 (T1T4). Thus, the use of T1T2 gains to represent non-training gains 
455 may have underestimated true T1T3 and T1T4 non-training gains. According to previous research,

456 non-training gains on cognitive tests over no-training periods decrease in size across test sessions (e.g.,

457 Bartels, Wegrzyn, Wiedl, Ackermann, \& Ehrenreich, 2010; Collie, Maruff, Darby, \& McStephen,

458 2003; Kohnen, Nickels, \& Coltheart, 2010). Thus, if T1T3 and T1T4 non-training gains were solely

459 responsible for any "valid training gains" found in this study (i.e., gains marked ** in Figure 3 that are

460 both significantly larger than 0 and significantly larger than T1T2 gains) then (1) T1T3 gains should be

461 less than double T1T2 gains, (2) T1T4 gains should be less then triple T1T2 gains, and (3) both groups

462 should show very similar-sized gains (since type of training should no effect). Examination of Figure 3

463 reveals that these criteria did not apply to gains in trained irregular word accuracy, nonword reading

464 accuracy, nonword reading fluency, or word reading fluency. This reinforces the conclusion that these

465 gains reflect valid training gains. However, these criteria did apply to untrained irregular word

466 accuracy and reading comprehension, which questions whether the gains in these outcomes were valid

467 training gains, as defined by the criteria used by McArthur et al. (in press).

Given the apparently reliable effects of sight word and phonics training on trained irregular word

accuracy, nonword reading accuracy, nonword reading fluency, and word reading fluency, but the questionable effects of this training on irregular word accuracy and reading comprehension gains, it is

471 clear that a randomised controlled trial is now needed to compare the effect of phonics and sight word

472 training to an untrained control group and a trained control group (e.g., maths training). Since

473 McArthur et al. and the current study both found that order of training phonics and sight word reading

474 had a limited effect on outcomes in 7- to 12-year-old poor readers, such studies could focus on training

475 phonics and sight words in isolation. This would reduce the length of the experiment from 6 months

476 (i.e., including a test-retest period, and two training periods) down to just 2 months (comprising a

477 single training period). Unlike the current study, such a randomised control trial that included both an

478 untrained control group and a trained control group would allow the explicit tracking of non-training 
479 effects across all test sessions. In the case of a trained control group, such non-training effects would 480 include training-related Hawthorne effects, which are improvements in reading and spelling outcomes 481 arising from an awareness of being involved in training. This new randomised controlled study may 482 also benefit from including a passage reading test as an outcome measure to extend our understanding 483 of the effects of phonics and sight word training in poor readers.

$484 \quad$ A second limitation of both the current study and McArthur et al. (2013) was that the reading 485 gains made by poor readers - though statistically significant, reliable, and large in effect size - did not 486 "propel" children's reading into the average range. This does not represent a failure of phonics or sight 487 word training. Instead, it represents the degree of difficulty of treating reading in children who are, by 488 definition, "reading resistant". Now we have established that phonics and sight word training both have 489 reliable effects on typically heterogeneous groups of children with poor reading on average, we can 490 start to focus on how such effects can be maximised in children with different patterns of reading 491 impairment.

A third limitation of this study, which was not considered by McArthur et al. (in press), and in 493 some ways may be considered a strength, is the highly mixed educational backgrounds of the poor 494 readers in both studies. The country in which both studies were conducted (i.e., Australia) has a highly 495 unregulated approach to reading. The national curriculum is too vague to provide clear advice to 496 teachers about how much time should be spent on different reading strategies, and the National Inquiry 497 of the Teaching of Reading in Australia revealed that tertiary teaching courses allocate less than 5-10\% 498 of course time to teaching student teachers how to teach reading (Rowe, 2005). Adding to this 499 confusion is the fact that over the last 5 to 10 years, evidence-based schools have been moving away 500 from a strictly "whole language" approach to more mixed approaches that include phonics instruction. 501 This means that the children in this study were receiving very different "mixes" of reading instruction 502 at their various schools. On the one hand, this is problematic because it means that this study cannot 
503 provide any insight into how phonics training paired with sight word training might interact with

504 different types of instruction at school. However, on the other hand, the fact that two studies (i.e., the

505 original study and the current study) have found similar effects of phonics and sight training in groups

506 of poor readers from very different educational backgrounds attests to the usefulness of these

507 instructional strategies English-speaking countries where the regulation of the teaching of reading is

508 poor.

\section{Conclusion}

510

In sum, McArthur et al. (in press) conducted the first controlled group trial to measure the effect

511 of specific sight word training in children with poor reading, and compare the effects of specific sight

512 word training to specific phonics training in the same. Given the importance of discovering ways to

513 treat poor readers to minimize their risk of academic failure and poor emotional health, combined with

514 current concerns about the lack of direct replication of important scientific effects (Asendorpf et al.,

515 2013; Yong 2013), the aim of this study was the replicate the methods of McArthur et al. to test the

516 replicability of their findings. The current study replicated the majority of McArthur et al.'s effects.

517 Thus, the current study joins McArthur et al. in suggesting that specific sight word training paired with

518 specific phonics training has large and significant valid treatment effects in typical samples of poor

519 readers. It also supports the idea that poor readers should be taught to read via both phonics and sight

520 word strategies (e.g., Heilman, 1968; Nicolson, 2005). 
522 We would like to thank all the children and parents for the time and effort they invested in this

523 research. We would like to thank Shane Davis, Vicky Kadoglou, and all the people at Literacy Planet

524 for providing the training programs for this trial, and their enthusiastic and unerring support for this

525 project and reading research. 
529 Recommendations for increasing replicability in psychology. European Journal of Personality, 27, $530 \quad 108-119$. healthy adults: A longitudinal study on frequent repetitive cognitive testing. BMC Neuroscience, 11, 118-130.

Broom, Y. M., \& Doctor, E. A. (1995). Developmental surface dyslexia: A case study of the

Castles, A., Coltheart, M., Larsen, L., Jones, P., Saunders, S., \& McArthur, G. (2009). Assessing the basic components of reading: A revision of the Castles and Coltheart test with new norms. Australian Journal of Learning Difficulties, 14, 67-88. cognitive test performance of neurologically normal individuals assessed at brief test-retest intervals. Journal Of The International Neuropsychological Society, 9, 419-428. 
Ehri, L. C., Nunes, S. R., Stahl, S. A., \& Willows, D. M. (2001). Systematic phonics instruction

553 helps students learn to reading: evidence from the national reading panel's meta-analysis. Review of

554 Educational Research, 71, 393-447.

555 Galuschka, K., Ise, E., Krick, K., \& Schulte-Körne, G. (2014) Effectiveness of Treatment

556 Approaches for Children and Adolescents with Reading Disabilities: A Meta-Analysis of Randomized

557 Controlled Trials. PLoS ONE, 9, e89900.

558 Goulandris, N. K. , \& Snowling, M. (1991). Visual memory deficits: a plausible cause of

559 developmental dyslexia? Evidence from a single case study. Cognitive Neuropsychology, 8, 127-154.

560 Heilman, A. W. (1968). Phonics in Proper Perspective, 2 ${ }^{\text {nd }}$ Edition. Columbus, Ohio: Charles E.

561 Merril.

562 Hulme, C., \& Snowling. M. (2009). Developmental Disorders of Language, Learning and

563 Cognition. London, UK: Wiley-Blackwell.

564 Ioannidis, J. (2012). Why Science Is Not Necessarily Self-Correcting. Perspectives on 565 Psychological Science, 7, 645-654.

566 Kaufman, A., \& Kaufman, N. (2004). Kaufman Brief Intelligence Test $2^{\text {nd }}$ Edition. Circle Pines, 567 USA: AGS.

568 Kohnen, S., Nickels, L. \& Coltheart, M. (2010). Skill Generalisation in Teaching Spelling to 569 Children with Learning Difficulties. Australian Journal of Learning Difficulties, 15, 115-129.

$570 \quad$ Mahmoud, S. (2011). MinimPy ${ }^{\odot}$ (Version 0.3) [software].

571 McArthur, G., Castles, A., Kohnen, S., Larsen, L., Jones, K., Anandakumar, T., \& Banales, E. (in 572 press). Sight word and phonics training in children with dyslexia. Journal of Learning Disabilities.

573 McArthur, G., Eve, P., Jones, K., Banales, E., Kohnen, S., Anandakumar, T., Larsen, L.,

574 Marinus, E., Wang, H.-C., \& Castles, A. (2012). Phonics training for English-speaking poor

575 readers. Cochrane Database of Systematic Reviews, 12. 
McArthur, G., Jones, K., Anandakumar, T., Castles, A., Larsen, L., \& Coltheart, M. (2013). A

577 Test of Everyday Reading Comprehension (TERC). Australian Journal of Learning Difficulties, 18, $578 \quad 35-85$.

579 Nicholson, T. (2005). The Phonics Handbook. London, UK: Whurr.

580 Pashler, H., \& Harris, C. (2012). Is the Replicability Crisis Overblown? Three Arguments

581 Examined. Perspectives on Psychological Science, 7, 531-536.

582 Plaut, D. C., McClelland, J. L., Seidenberg, M. S., \& Patterson, K. (1996). Understanding normal 583 and impaired word reading: Computational principles in quasi-regular domains. Psychological Review, $584103,56-115$.

586 Australia: ACER.

587 Schulz, K., Altman, D., \& Moher, D. (2010). CONSORT 2010 Statement: Updated guidelines for 588 reporting parallel group randomised trials. Annals of Internal Medicine, 152, 1-7.

589 Torgeson, J., Wagner, R., \& Rashotte, C. (1997). Test of Word Reading Efficiency. Austin, TX:

590 Pro-Ed.

591 Wagenmakers, E., Wetzels, R., Borsboom, D., van der Maas, H. L., \& Kievit, R. (2012). An

592 Agenda for Purely Confirmatory Research. Perspectives on Psychological Science, 7, 632-638.

593 Yong, E. (2012). Bad copy: In the wake of high-profile controversies, psychologists are facing up 594 to problems with replication. Nature, 485, 298-30. 


\section{Table $\mathbf{1}$ (on next page)}

Training effects in McArthur et al. (2013) and the current study for Group 1 and Group 2.

T1T2, T1T3.and T1T4 represent gains in raw scores from Test 1 (before training) to Test 2 (after 8 weeks of no training), Test 3 (after the first 8 weeks of phonics in Group 1 or sight word training in Group 2), and Test 4 (after 16 weeks of training), respectively. Effect sizes (ES; Cohen's d) in bold indicate training gains significantly larger than T1T2. ESs of 0.3, 0.5, and 0.8 were considered small (S), medium (M), and large (L), respectively. 
Table 1

Training effects in McArthur et al. (2013) and the current study for Group 1 and Group 2. T1T2, T1T3. and T1T4 represent gains in raw scores from Test 1 (before training) to Test 2 (after 8 weeks of no training), Test 3 (after the first 8 weeks of phonics in Group 1 or sight word training in Group 2), and Test 4 (after 16 weeks of training), respectively. Effect sizes (ES; Cohen's d) in bold indicate training gains significantly larger than T1T2. ESs of 0.3, 0.5, and 0.8 were considered small (S), medium (M), and large (L), respectively.

\begin{tabular}{|c|c|c|c|c|c|c|c|c|c|c|c|c|}
\hline & \multicolumn{6}{|c|}{ Group 1} & \multicolumn{6}{|c|}{ Group 2} \\
\hline & \multicolumn{3}{|c|}{ McArthur et al. $(\mathrm{N}=36)$} & \multicolumn{3}{|c|}{ Current $(\mathrm{N}=41)$} & \multicolumn{3}{|c|}{ McArthur et al. $(\mathrm{N}=36)$} & \multicolumn{3}{|c|}{ Current $(\mathrm{N}=44)$} \\
\hline & M & SD & ES & M & $\mathrm{SD}$ & ES & $\mathrm{M}$ & $\mathrm{SD}$ & ES & M & SD & ES \\
\hline \multicolumn{13}{|c|}{ Trained irregular word accuracy } \\
\hline T1T2 & 1.06 & 1.72 & $0.6(\mathrm{M})$ & 0.59 & 2.90 & $0.2(\mathrm{~S})$ & 1.31 & 2.54 & $0.5(\mathrm{M})$ & 0.98 & 2.37 & $0.4(\mathrm{~S})$ \\
\hline T1T3 & 2.67 & 2.12 & $1.3(\mathrm{~L})$ & 2.08 & 2.98 & 0.7 (M-L) & 5.25 & 3.52 & $1.5(\mathrm{~L})$ & 2.73 & 2.61 & $1.0(\mathrm{~L})$ \\
\hline $\mathrm{T} 1 \mathrm{~T} 4$ & 5.14 & 3.32 & $1.6(\mathrm{~L})$ & 3.39 & 3.25 & $1.0(\mathrm{~L})$ & 5.14 & 4.26 & $1.2(\mathrm{~L})$ & 3.39 & 2.44 & $1.4(\mathrm{~L})$ \\
\hline \multicolumn{13}{|c|}{ Untrained irregular word accuracy } \\
\hline $\mathrm{T} 1 \mathrm{~T} 2$ & 1.08 & 1.57 & $0.7(\mathrm{M})$ & 1.34 & 2.55 & $0.5(\mathrm{M})$ & 1.31 & 1.80 & $0.7(\mathrm{M})$ & 1.39 & 2.01 & $0.7(\mathrm{M})$ \\
\hline T1T3 & 2.08 & 1.76 & $1.2(\mathrm{~L})$ & 2.23 & 2.81 & $0.8(\mathrm{~L})$ & 2.53 & 2.02 & $1.2(\mathrm{~L})$ & 2.11 & 2.42 & $0.9(\mathrm{~L})$ \\
\hline T1T4 & 3.69 & 2.51 & $1.5(\mathrm{~L})$ & 2.68 & 2.35 & $1.1(\mathrm{~L})$ & 2.39 & 2.35 & $1.0(\mathrm{~L})$ & 2.86 & 2.61 & $1.1(\mathrm{~L})$ \\
\hline \multicolumn{13}{|c|}{ Nonword accuracy } \\
\hline T1T2 & 1.28 & 3.70 & $0.4(\mathrm{~S})$ & 0.07 & 4.33 & $0.0(\mathrm{~S})$ & 0.17 & 3.79 & $0.0(\mathrm{~S})$ & -0.88 & 4.26 & $-0.2(\mathrm{~S})$ \\
\hline T1T3 & 2.75 & 4.12 & $0.7(\mathrm{M})$ & 1.78 & 6.21 & $0.3(\mathrm{~S})^{*}$ & 1.42 & 3.96 & $0.4(\mathrm{~S})$ & -0.37 & 3.55 & $-0.1(\mathrm{~S})^{*}$ \\
\hline $\mathrm{T} 1 \mathrm{~T} 4$ & 3.00 & 3.96 & $0.8(\mathrm{~L})$ & 2.17 & 5.14 & $0.4(\mathrm{~S}) *$ & 3.64 & 4.89 & $0.7(\mathrm{M})$ & 1.23 & 3.26 & $0.4(\mathrm{~S}-\mathrm{M})$ \\
\hline \multicolumn{13}{|c|}{ Nonword fluency } \\
\hline $\mathrm{T} 1 \mathrm{~T} 2$ & 2.03 & 4.55 & $0.4(\mathrm{~S})$ & -0.66 & 3.98 & $-0.2(\mathrm{~S})$ & 1.78 & 4.70 & $0.4(\mathrm{~S})$ & 0.48 & 4.32 & $0.1(\mathrm{~S})$ \\
\hline $\mathrm{T} 1 \mathrm{~T} 3$ & 3.72 & 4.69 & $0.8(\mathrm{~L})$ & 1.17 & 4.85 & $0.2(\mathrm{~S})^{*}$ & 3.08 & 4.11 & $0.8(\mathrm{~L})$ & 1.00 & 3.94 & $0.2(\mathrm{~S})$ \\
\hline $\mathrm{T} 1 \mathrm{~T} 4$ & 4.17 & 4.78 & $0.9(\mathrm{~L})$ & 1.44 & 4.66 & $0.3(\mathrm{~S})^{*}$ & 3.03 & 5.05 & $0.6(\mathrm{M})$ & 2.86 & 4.28 & 0.7 (M-L)* \\
\hline \multicolumn{13}{|c|}{ Sight word fluency } \\
\hline $\mathrm{T} 1 \mathrm{~T} 2$ & 3.97 & 5.41 & $0.7(\mathrm{M})$ & 2.66 & 6.28 & $0.4(\mathrm{~S})$ & 3.25 & 7.38 & $0.4(\mathrm{~S})$ & 2.64 & 4.83 & $0.6(\mathrm{M})$ \\
\hline T1T3 & 6.69 & 5.70 & $1.2(\mathrm{~L})$ & 5.22 & 5.85 & $0.9(\mathrm{~L})$ & 4.42 & 5.03 & $0.9(\mathrm{~L})$ & 6.61 & 4.77 & $1.4(\mathrm{~L})$ \\
\hline T1T4 & 7.33 & 7.68 & $1.0(\mathrm{~L})$ & 8.83 & 4.99 & $1.8(\mathrm{~L})$ & 9.53 & 11.26 & $0.8(\mathrm{~L})$ & 6.73 & 5.81 & $1.2(\mathrm{~L})$ \\
\hline \multicolumn{13}{|c|}{ Reading comprehension } \\
\hline $\mathrm{T} 1 \mathrm{~T} 2$ & 1.83 & 2.96 & $0.6(\mathrm{M})$ & 1.17 & 2.19 & $0.5(\mathrm{M})$ & 1.89 & 3.00 & $0.6(\mathrm{M})$ & 1.23 & 2.53 & $0.4(\mathrm{M})$ \\
\hline T1T3 & 3.53 & 3.13 & $1.1(\mathrm{~L})$ & 1.98 & 2.43 & $0.8(\mathrm{~L})^{*}$ & 3.56 & 3.97 & $0.9(\mathrm{~L})$ & 1.39 & 2.13 & $0.6(\mathrm{M})^{*}$ \\
\hline T1T4 & 4.78 & 4.32 & $1.1(\mathrm{~L})$ & 2.51 & 2.48 & $1.0(\mathrm{~L})$ & 4.22 & 4.28 & $1.0(\mathrm{~L})$ & 1.98 & 2.62 & $0.8(\mathrm{~L})$ \\
\hline
\end{tabular}




\section{Table 2(on next page)}

Screening and outcome measures

Means (M) and standard deviations (SD) for the screening and outcome measures. CC2 = Castles and Coltheart reading tests (Castles et al., 2009); $\Pi \pi=$ time training; $s=$ standard score; $z=z$ score; $r$ = raw score; $h=$ hours. 
Table 2

Means $(M)$ and standard deviations (SD) for the screening and outcome measures.

$C C 2=$ Castles and Coltheart reading tests (Castles et al., 2009); TT = time training; $s$ $=$ standard score; $z=z$ score; $r=$ raw score; $h=$ hours.

\begin{tabular}{|c|c|c|c|c|c|}
\hline & & \multicolumn{2}{|c|}{ Group 1} & \multicolumn{2}{|c|}{ Group 2} \\
\hline & & $\mathbf{M}$ & SD & $\mathbf{M}$ & SD \\
\hline \multirow{5}{*}{ 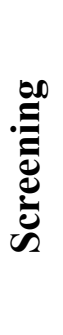 } & Age (years) & 9.53 & 1.51 & 9.58 & 1.45 \\
\hline & Non-verbal IQ (s) & 97.02 & 15.75 & 97.57 & 16.45 \\
\hline & CC2 Irregular words (z) & -1.42 & 0.65 & -1.37 & .75 \\
\hline & CC2 Nonwords (z) & -1.66 & 0.57 & -1.62 & .67 \\
\hline & CC2 Regular words (z) & -1.61 & 0.54 & -1.57 & .46 \\
\hline \multirow{2}{*}{ 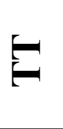 } & Sight word training $(\mathrm{h})$ & 14.46 & 3.66 & 14.89 & 3.66 \\
\hline & Phonics training $(\mathrm{h})$ & 14.53 & 3.29 & 14.37 & 2.90 \\
\hline \multirow{6}{*}{ 莺 } & Trained irregular accuracy (r) & 12.59 & 7.28 & 13.64 & 8.06 \\
\hline & Untrained irregular accuracy (r) & 11.34 & 7.31 & 12.59 & 8.44 \\
\hline & Nonword reading accuracy (r) & 9.93 & 7.11 & 12.65 & 7.05 \\
\hline & Nonword reading fluency (r) & 11.34 & 8.16 & 11.82 & 8.53 \\
\hline & Word reading fluency $(\mathrm{r})$ & 42.88 & 16.79 & 43.16 & 18.65 \\
\hline & Reading comprehension (r) & 12.32 & 5.21 & 12.32 & 6.12 \\
\hline \multirow{6}{*}{$\stackrel{\sim}{\tilde{g}}$} & Trained irregular accuracy (r) & 13.17 & 7.871 & 14.61 & 8.23 \\
\hline & Untrained irregular accuracy (r) & 12.68 & 7.796 & 13.98 & 8.77 \\
\hline & Nonword reading accuracy (r) & 10.00 & 7.183 & 12.02 & 7.65 \\
\hline & Nonword reading fluency (r) & 10.68 & 7.715 & 12.30 & 8.48 \\
\hline & Word reading fluency $(r)$ & 45.54 & 15.82 & 45.80 & 19.00 \\
\hline & Reading comprehension (r) & 13.49 & 5.060 & 13.55 & 5.57 \\
\hline \multirow{6}{*}{$\stackrel{n}{s}$} & Trained irregular accuracy (r) & 14.90 & 7.38 & 16.36 & 8.34 \\
\hline & Untrained irregular accuracy (r) & 13.82 & 7.82 & 14.70 & 8.48 \\
\hline & Nonword reading accuracy (r) & 11.71 & 7.83 & 12.45 & 7.73 \\
\hline & Nonword reading fluency (r) & 12.51 & 8.44 & 12.82 & 8.96 \\
\hline & Word reading fluency $(r)$ & 48.10 & 16.39 & 49.77 & 18.81 \\
\hline & Reading comprehension (r) & 14.29 & 4.56 & 13.70 & 5.50 \\
\hline \multirow{6}{*}{ 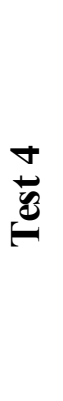 } & Trained irregular accuracy (r) & 15.98 & 7.023 & 17.02 & 8.02 \\
\hline & Untrained irregular accuracy (r) & 14.02 & 7.630 & 15.45 & 8.67 \\
\hline & Nonword reading accuracy (r) & 12.10 & 7.896 & 14.16 & 7.95 \\
\hline & Nonword reading fluency $(r)$ & 12.78 & 8.575 & 14.68 & 8.49 \\
\hline & Word reading fluency $(\mathrm{r})$ & 51.71 & 16.805 & 49.89 & 19.32 \\
\hline & Reading comprehension (r) & 14.83 & 4.494 & 14.30 & 5.16 \\
\hline
\end{tabular}


1

Testing and training phases for each group

The order of testing and training phases completed by the two groups

\begin{tabular}{lll}
\hline & Group 1 & Group 2 \\
& $\mathbf{N = 4 1}$ & $\mathbf{N}=\mathbf{4 4}$ \\
\hline Test 1 & Screening measures & Screening measures \\
2-3 hours & Outcome measures & Outcome measures \\
\hline No training & No training & No training \\
8 weeks & & \\
\hline
\end{tabular}

Test 2

2-3 hours

Outcome measures $\quad$ Outcome measures

Train 1

8 weeks

Phonics

Sight words

Test 3

2-3 hours

Outcome measures $\quad$ Outcome measures

Train 2

8 weeks

Sight words

Phonics

Test 4

2-3 hours

Outcome measures

Outcome measures 
2

Flow diagram

The number of children who participated in each stage of the study 
Screened for eligibility 160

\begin{tabular}{|c|c|c|c|}
\hline \multirow{2}{*}{\multicolumn{2}{|c|}{$\rightarrow$}} & \begin{tabular}{|l} 
Did not meet criteria \\
Declined participation
\end{tabular} & $\begin{array}{l}30 \\
10 \\
\end{array}$ \\
\hline & & & \\
\hline \multicolumn{4}{|c|}{ Allocation } \\
\hline \multicolumn{2}{|l|}{$\downarrow$} & \multicolumn{2}{|l|}{$\downarrow$} \\
\hline Started Test 1 & 59 & Started Test 1 & 61 \\
\hline Dropout & 0 & Dropout & 0 \\
\hline Completed Test 1 & 59 & $\underset{\text { Completed Test } 1}{\downarrow}$ & 61 \\
\hline Started no training period & 59 & Started no training period & 61 \\
\hline Dropout & 3 & Dropout & 3 \\
\hline \multicolumn{2}{|l|}{$\downarrow$} & \multicolumn{2}{|l|}{$\downarrow$} \\
\hline Started Test 2 & 56 & Started Test 2 & 58 \\
\hline Dropout & 0 & Dropout & 0 \\
\hline $\begin{array}{c}\text { Completed Test } 2 \\
\downarrow\end{array}$ & 56 & $\begin{array}{r}\text { Completed Test } 2 \\
\downarrow\end{array}$ & 58 \\
\hline Started phonics training & 56 & Started sight word training & 58 \\
\hline Dropout & 8 & Dropout & 5 \\
\hline Incomplete training & 2 & Incomplete training & 0 \\
\hline \multicolumn{2}{|l|}{$\downarrow$} & \multicolumn{2}{|l|}{$\downarrow$} \\
\hline Started Test 3 & 46 & Started Test 1 & 53 \\
\hline Dropout & 0 & Dropout & 0 \\
\hline$\frac{\text { Completed Test } 3}{\downarrow}$ & 46 & $\begin{array}{r}\text { Completed Test } 1 \\
\downarrow\end{array}$ & 53 \\
\hline Started sight word training & 46 & Started phonics training & 53 \\
\hline Dropout & 5 & Dropout & 6 \\
\hline Incomplete training & 0 & Incomplete training & 2 \\
\hline$\downarrow$ & 41 & $\underset{\downarrow}{\text { Completed phonics training }}$ & 45 \\
\hline Started Test 4 & 41 & Started Test 4 & 45 \\
\hline Dropout & 0 & Dropout & 0 \\
\hline Completed Test 4 & 41 & Completed Test 4 & 45 \\
\hline$\downarrow$ & & $\downarrow$ & \\
\hline Excluded from analysis & 0 & Excluded from analysis & 1 \\
\hline Analyseerld deviewing PDF I (2014:10:2922:4:0 & :R耳YIIEM & APA2015)ysed & 44 \\
\hline
\end{tabular}


3

Gains in outcome measures

Group means and $95 \%$ confidence intervals for gains in raw scores for each outcome measure for the two groups 
Trained irregular word accuracy

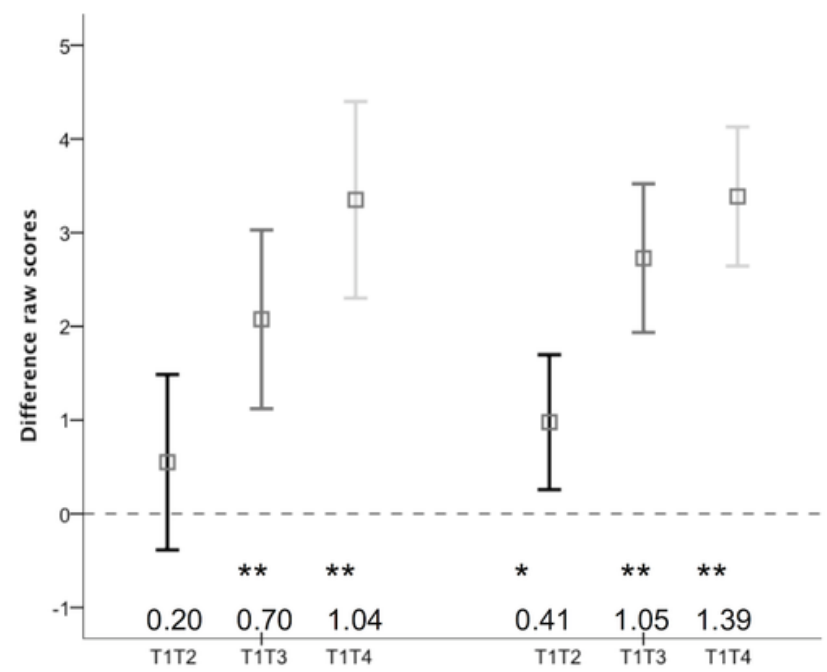

Nonword reading accuracy

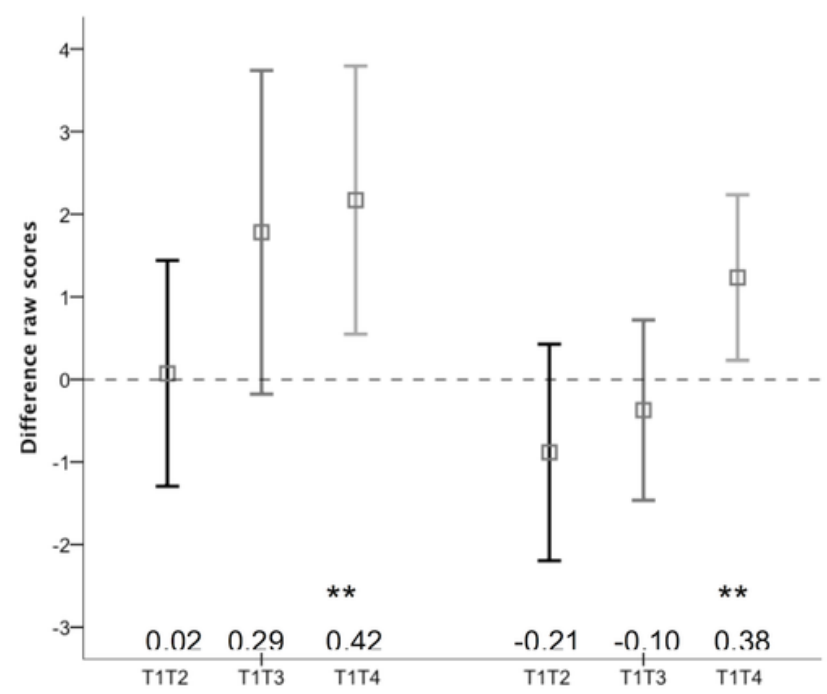

Word reading fluency

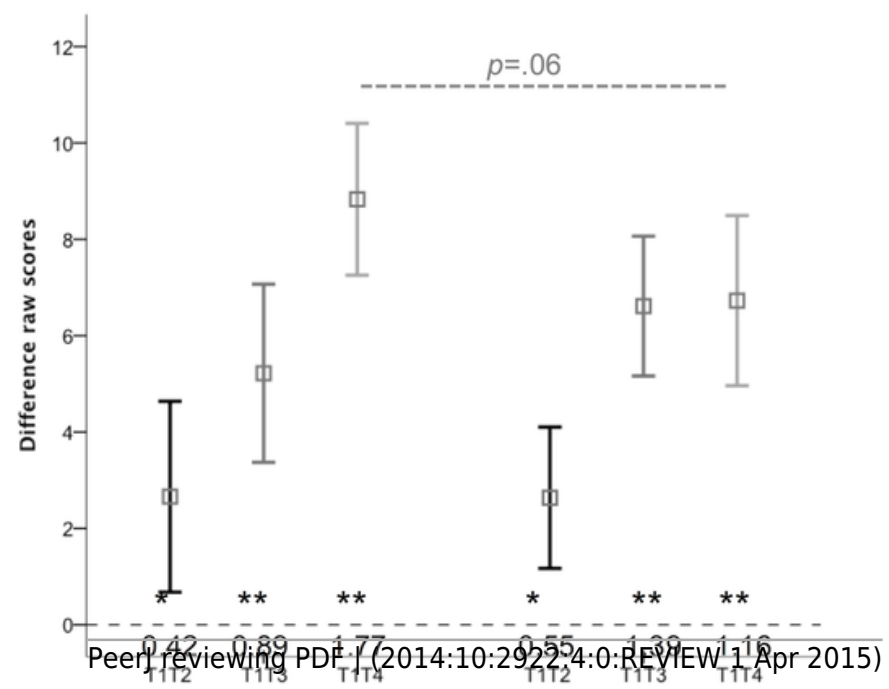

Untrained irregular word accuracy

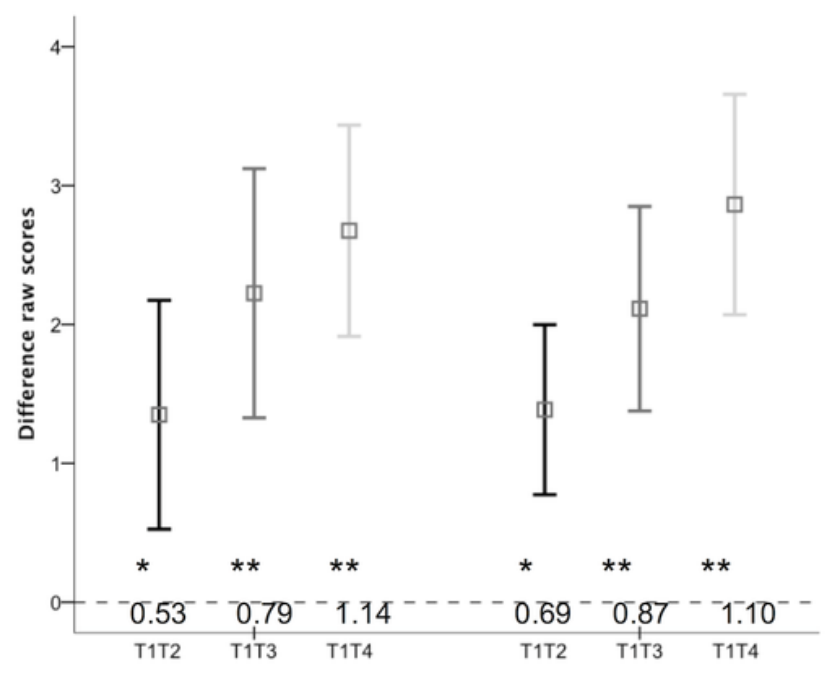

Nonword reading fluency

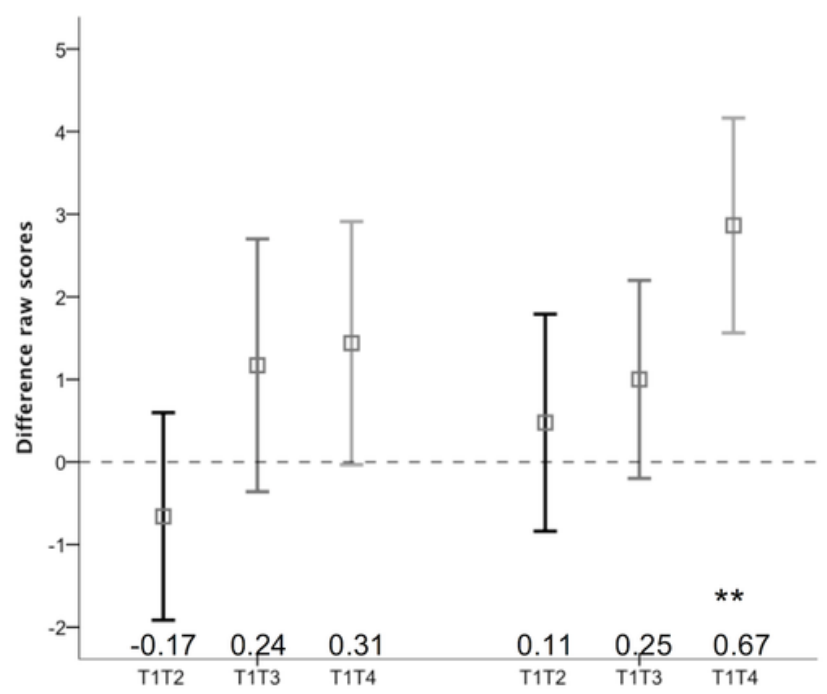

Reading comprehension

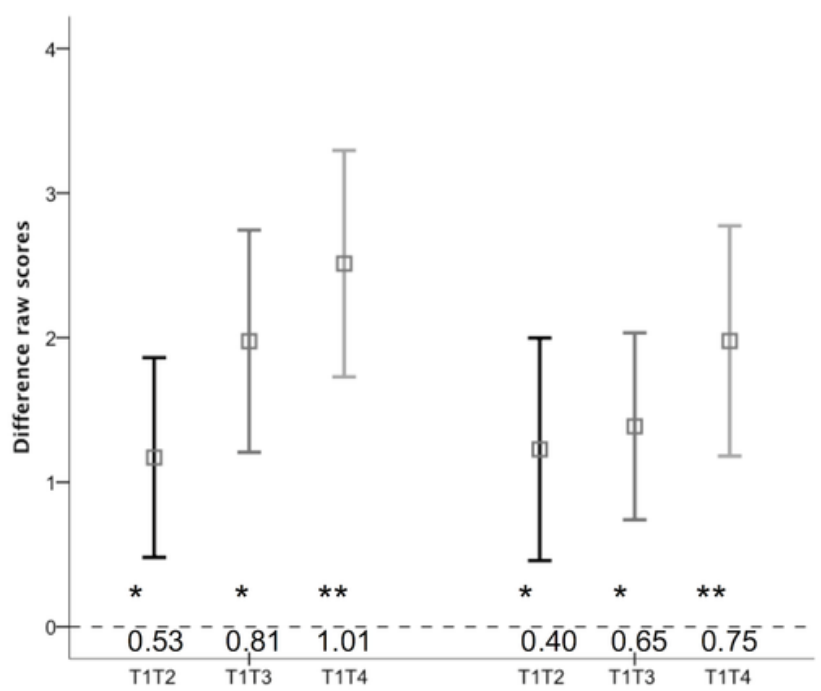

